\title{
The Difficulty of Moral Perfectionism
}

Cavell and Diamond on Self-understanding, Disagreement and Nonsense in Ethics

\section{Stefano Di Brisco}

\section{(2) OpenEdition}

1 Journals

Electronic version

URL: http://journals.openedition.org/ejpap/913

DOI: 10.4000/ejpap.913

ISSN: 2036-4091

Publisher

Associazione Pragma

Electronic reference

Stefano Di Brisco, «The Difficulty of Moral Perfectionism », European Journal of Pragmatism and

American Philosophy [Online], II-2 | 2010, Online since 21 December 2010, connection on 01 May 2019. URL : http://journals.openedition.org/ejpap/913 ; DOI : 10.4000/ejpap.913

This text was automatically generated on 1 May 2019.

\section{(c) $(9) \odot$}

Author retains copyright and grants the European Journal of Pragmatism and American Philosophy right of first publication with the work simultaneously licensed under a Creative Commons AttributionNonCommercial-NoDerivatives 4.0 International License. 


\title{
The Difficulty of Moral Perfectionism
}

\author{
Cavell and Diamond on Self-understanding, Disagreement and Nonsense \\ in Ethics
}

Stefano Di Brisco

1 In what follows I want to consider a kind of inexpressiveness that can characterize our moral experience. The acknowledgement of the possibility of failure in trying to word the world - in finding adequate means of expression for our condition - deeply informs Cora Diamond's conception of language and moral thought as well as her philosophical method. In particular, in her paper The Difficulty of Reality and the Difficulty of Philosophy (hereafter DRDP), Diamond is concerned with:

[...] experiences in which we take something in reality to be resistant to our thinking it, or possibly to be painful in its inexplicability, difficult in that way, or perhaps awesome and astonishing in its inexplicability. We take things so. And the things we take so may simply not, to others, present that kind of difficulty, of being hard or impossible or agonizing to get one's mind around. (DRDP: 99)

2 A difficulty of reality in Diamond's sense is thus a resistance by reality to one's ordinary modes of thinking and talking, the feeling of a mismatch between concepts and experience in which it is the nature of experience itself that deprives one of the words suitable to contain it. Importantly, this kind of difficulty may lead to a philosophical inadequacy to think these aspects of experience.

In this paper I want to show how a particular kind of moral conflict can be perspicuously described as a difficulty of reality. This conflict occurs when we lose the ability to conceive the moral world we inhabit as ours, when, that is, our self-conceptions clash with the requirements of morality and we find ourselves in the position of not being able to say what "morality" means for us anymore.

4 Stanley Cavell speaks in this vicinity of the possibility of repudiating morality when it threatens our integrity (Cavell 1979: 269). This distance between the subject and the world, the self and morality, which, in Cavell's account of perfectionism, is a precondition for the development of an authentic moral perspective, is nonetheless neglected by meta- 
ethical analyses in which the prominent occurrences of ethical disagreements pertain principally to the correct application of evaluative terms. Indeed, if we construct a picture of disagreement according to which what morally opposes us is the assessment of a fact - Is death a just punishment for a prisoner? - or a judgment about a course of action - Is it courageous to commit suicide in the name of an ideal? -, there is no space for a question about the sources of the interest we may take in morality on the whole.

5 I begin by sketching Cavell's analysis of disagreement in the light of his discussion of moral rationality. Then I will connect the topic with Diamond's notion of the "difficulty of reality," developing the link between Diamond's and Cavell's thought by using as an example a dialogue taken from Richard Yates' novel Revolutionary Road.

$$
\text { *** }
$$

6 In part III of The Claim of Reason Cavell criticizes the philosophical conception according to which the persistence of disagreement in some moral disputes compromises the possibility of considering moral thought as fully rational. According to Cavell, the need to anchor the rationality of moral discourse and thought in the resolution of every disagreement is a philosophical requirement laid down on the ground of an assumption about the nature of rationality and the role of moral argument. In particular, Cavell holds that a non-cognitivist analysis of disagreement rests upon the assumption that what renders an argument rational is its capacity to generate a shared conclusion from valid premises, and so that the aim of moral argument is to lead the parties towards the acceptance of such a conclusion (Cavell 1979: 254). This picture of moral rationality originates in an interest in comparing moral judgments with scientific ones, where the interest is informed by an empiricist conception of language as a neutral vehicle of contents - a conception that borrows from science and logic the epistemological standards of knowledge and objectivity (Cavell 1979: 173, 253). ${ }^{1}$ Cavell writes that:

7 If you begin by being struck with the peculiarity of ethical arguments as perhaps unsettleable, and struck with how different other questions are, then you will pick up examples from science which illustrate its capacity for agreement, and you will then have the idea, or illusion, that you know that, and why, science is rational and morality not (Cavell 1979: 263).

8 This is intended as a warning that the model of explanation we use determines the form of the problem under investigation. But it is not only a methodological reminder, for the empiricist picture of language also implies a stipulative conception of meaning, according to which the meanings of words are determined by the set of rules settled on the uses of the community of speakers. But if the meanings of the words we use were always already available, then there could not be any problem concerning the possibility of expression, or a difficulty in the way we use our words. So it is already possible to trace a link between Cavell's and Diamond's thought at this stage, since that conception of language has also been strongly resisted by Diamond. She writes that:

Empiricism makes it appear as if we could not help having whatever words we needed for our experience: words which were at least adequate to represent it to ourselves, because whenever words for a kind of experience are lacking there is no difficulty in coining new ones. The only problem there might be would lie in communication with others, and would come from our ignorance for the standard use of some words. (Diamond 1988: 270) 
9 In order to resist this instrumental picture of language, Cavell offers examples of arguments whose conclusion is characterized by rational disagreement: his aim is to show that what meta-ethics considers a lack of rationality is just a fact of ordinary language. According to Cavell, a philosophical assessment of moral rationality should begin with ordinary examples of moral discourse, taken from a real human context. Having these examples in view, we are in the position of seeing that the philosophical theses that deny the rationality of morality (because it does not present certain features of what is considered as paradigmatic of rationality, namely logic and science) depends itself upon an assumption about the concept of rationality and morality.

10 Against the idea of rationality as the capacity of arriving at a shared conclusion, Cavell points to competence as the fundamental feature of a conversation. It is our competence as speakers indeed that is questioned in a moral conversation, and not the rationality of ethics on the whole. This notion of competence is tied to the idea of meaning as depending on our capacity to master ordinary language. Cavell writes that in moral disagreements:

The point is to determine what position you are taking, that is to say, what position you are taking responsibility for - and whether it is one I can respect. What is at stake in such discussions is not, or not exactly whether you know our world, but whether, or to what extent, we are to live in the same moral universe. What is at stake in such examples [...] is not the validity of morality as a whole, but the nature or quality of our relationship to one another. (Cavell 1979: 268)

11 Cavell holds that it is crucial, in moral conversations, to leave open the possibility of disagreement: the presumed lack of rationality of moral discourse turns out to be our permanent possibility of questioning the practices and the concepts we share. That is, this possibility is constitutive of the kind of rationality proper to moral discourse, and has a central role in the process of coming to know ourselves and others. Cavell goes on to say that:

discussion is necessary because our responsibilities, the extensions of our cares and commitments, and the implications of our conduct, are not obvious; because the self is not obvious to the self. To the extent that that responsibility is the subject of moral argument, what makes moral argument rational is not the assumption that there is in every situation one thing which ought to be done and that this may be known, nor the assumption that we can always come to agreement about what ought to be done on the basis of rational methods. Its rationality lies in following the methods which lead to a knowledge of our own position, of where we stand; in short, to a knowledge and definition of ourselves. (Cavell 1979: 312)

12 In moral disagreements we face the problem of knowing ourselves and others. From this point of view a moral conversation is a way to assess the status of a relationship (with myself or others): in it we verify if and to what extent we can recognize each other as members of the same moral community, if we can go on speaking, and so on. But this problem is eluded by moral theories which focus on a conception of language as an enclosed space of given activities, a perimeter of fixed rules in which the application of concepts is not something we do, but a set of predetermined possibilities that we select in accordance with the contingencies of conversation. Cavell holds that this conception of language hides precisely the responsibility for the moral position we take.

13 At this point it might be useful to connect this analysis of disagreement to Cavell's diagnosis of the relationship between philosophy and skepticism. In Natural and Conventional, Cavell writes: 
In making the knowledge of others a metaphysical difficulty, philosophers deny how real the practical difficulty is of coming to know another person, and how little we can reveal of ourselves to another's gaze, or bear of it. Doubtless such denials are part of the motive which sustains metaphysical difficulties. (Cavell 1979: 90)

According to Cavell, skepticism about other minds emerges from the sense of separateness and limitation we may experience with respect to the knowledge of others. The kind of response philosophy of mind has traditionally offered to this skepticism is deflected in so far as it eludes the problem of the limitation of our knowledge, by attempting to show that skeptical experience is empty. This is reflected, again, in a conception of language and of the use of concepts as a set of fixed rules that we simply apply, and beyond which there is nothing. That is to say that philosophy tries to face skepticism by denying the very possibility of experiencing the limitation of our knowledge, by denying in that way what we may call the "truth of skepticism." Similarly, ethical theories, which see in the fact of disagreement the impossibility of a fully rational moral thought, elude the difficulty of experiencing the limitation of morality. What is at stake in moral discourse and in moral thought is the responsibility for the position we take, and the possibility of calling into question such a position in a disagreement defines the kind of rationality we have. The philosophical requirement of a moral rationality, that must be capable of settling every disagreement, reflects the wish to avoid a responsibility we do not want. As Cavell puts it:

Morality must leave itself open to repudiation; it provides one possibility of settling conflict, a way of encompassing conflict which allows the continuance of personal relationship against the hard and apparently inevitable fact of misunderstanding, mutually incompatible wishes, commitments, loyalties, interests and needs, a way of mending relationships and maintaining the self in opposition to itself or others. Other ways of settling or encompassing conflict are provided by politics, religion, love and forgiveness, rebellion and withdrawal. (Cavell 1979: 269)

The possibility of seeing morality as limited is a crucial point for Cavell. Moral theories express the desire of a final assessment of every action and conflict: they represent an attempt to establish once and for all what we regard as right and important, and what is not. In this way, it seems that every limitation or inapplicability of an ethical theory means the failure of morality as a whole. But, according to Cavell, this is a moralization of morality, that is, the tendency to understand - through the distinctions and the intellectual instruments of moral theories - every situation and every human context, taking for granted both that they belong to the domain of morality and a certain concept of morality. A non-moralistic conception of morality must instead admit the possibility of seeing it as limited, but also that its domain is not limitable in advance - that its domain is not given - because there is no principle or rule that establishes what is important or of value for us. This is the reason why Cavell affirms the possibility of:

a position whose excellence we cannot deny, taken by persons we are not willing or able to dismiss, but which, morally, would have to be called wrong. And this has provided a major theme of modern literature: the salvation of the self through the repudiation of morality. (Cavell 1979: 269)

I think in this passage is adumbrated the theme of moral perfectionism, that Cavell developed in his works after The Claim of Reason. Indeed, it is only by acknowledging the limitation of morality that we can see the possibility of a conflict between our selfconception and the requirements of morality. In pointing to an apparent irresolvable conflict or a deep tension between the requirements of morality and the self-understanding that conditions them, the idea of 
"repudiation" might suggest a kind of skepticism concerning the reality of moral values and the normativity of moral thought. For if morality were something that could be repudiated when it conflicts with other, non-moral considerations or reasons, then one's assent to it would be just a matter of conventions and habits. This is the reason why Raimond Gaita criticizes Cavell's talking of "repudiation." Gaita says:

Situations which might prompt someone to say that morality finds its limits are various and they do not instantiate a single concept, 'the limits of morality.' Nothing, I think, that anyone might seriously mean by it need lead us, under pain of superficiality or naivety, to acknowledge that there are things that human beings do that are above or below the conceptual reach of a sober remorse. But is that not to deny that morality must leave itself open to repudiation? (Gaita 1991: 240)

The answer to Gaita's question depends on what we takes 'morality' to mean when we say that it can be repudiated. I think that Gaita is right about Cavell's lack of clarity on this theme, but I also think that it is possible to understand Cavell's talking of the 'limits of morality' and to accommodate it to Gaita's warning if we see it as a conflict within (what Bernard Williams would call) 'the ethical.' What can be repudiated by a person "whose excellence we cannot deny" is not the reality of values or the seriousness of remorse, but the conventional acceptance of the standards imposed by a culture. Anyway, for my purpose here it is not important to introduce the distinction between 'morality' and 'ethics.' What matters to me is to make clear that Cavell's point is about the importance of the relation between ethics and conceptions of the self, where a question about one's assent to the moral form of life is understood as a precondition for the development of a non-conformist moral perspective. Once we have recognized this, we can nonetheless accept Gaita's criticism that talking in general of the 'limits of morality' is not anything clear, because "whether [one] can be rightly judged to be morally serious will depend on the details of the example" (Gaita 1991: 242).

Following Cavell, I have characterized the meta-ethical analysis of disagreement in terms of deflection. This notion is used to specify a precise philosophical strategy: it does not mean simply to misdescribe a reality. It means to turn a certain kind of practical difficulty, which we want to elude, into an intellectual difficulty. Now, which is the practical difficulty in question? What kind of difficulty may we encounter in our ordinary moral life, which prompts us to intellectualize it? After all, Cavell claims that moral disagreement is a fact of our ordinary language, and that it does not compromise the rationality of morality. But there is a difficulty internal to our moral life, which is part of the experience we have of certain disagreements, and which is eclipsed in the way metathics has treated disagreement - that is, as a problem. To verify the plausibility of this position it is necessary to specify the notion of 'difficulty of reality,' and to provide an example of the kind of disagreement I have in mind.

In DRDP Diamond considers the "experience of the mind's not being able to encompass something that it encounters." She takes her examples of difficulty of reality from literature and poetry. These are various and complex examples, which refer to experiences of beauty and altruism, or of deep desperation and horror. I cannot dwell upon the details of these examples, but they all concern circumstances in our life that we are unable to describe, situations in which we experience a gulf between reality and our capacity to understand it. Such a difficulty may turn on a difficulty of philosophy too, 
which could contribute in hiding that reality, bringing us to consider a problem which is only similar to the one we were concerned with. Part of Diamond's concern is to show that the argumentative technique of analytic philosophy does not allow one to see that kind of difficulty, and so it deflects from reality, transferring the problem to the secure and controlled path of argumentation. Following one of Diamond's examples, we can see the deflection in the way Peter Singer turns Elizabeth Costello's sense of horror for our relationship with animals into a technical question about animal rights. The way in which Singer understands the question eclipses the fact that Costello's sense of horror arises from her perception of animals as lives of bodies exposed to death. By reducing the corporeity of animals to a fact analyzable in terms of objective features, Singer hides precisely Costello's source of interest in animals.

Let us go back to disagreement. We have seen that according to Cavell in a moral conversation we express our overall moral vision, for which we are responsible. The rationality of moral discourse lies in fact in the methods which lead us to a definition and to a better knowledge of ourselves and of others. Now, in what sense is the problem of knowledge of ourselves a difficulty which, in philosophy, we tend to deflect from? I want to suggest an example of moral conversation quoting a dialogue between the two protagonists of Richard Yates's Revolutionary Road.

Revolutionary Road is the story of April and Frank Wheeler, a young married couple living in the residential neighborhood of Revolutionary Hill, in Connecticut. Frank is a young office-worker for the Knox Company, April, an actress manquée, is a housewife and the mother of two children. Although they're perceived by their neighbors as a non conformist couple, their life flows as a suburban middle-class cliché. But Frank and April are dissatisfied with their condition, they recognize how oppressive and false their life is, and try to find a way to imagine their future. April, in particular, feels the burden of the "enormous, obscene delusion: the idea that people have to resign from real life and 'settle down' when they have a family," and so she thinks up a solution for her uneasiness and that of Frank. She thinks they have to sell their house in Revolutionary Road and move to Paris, where she would work as a secretary at NATO and where Frank, free from work, would take his time to "find his way." The project takes form, and they start putting up the house for sale. But an unexpected pregnancy, together with Frank's prospect of a job promotion, make things more complicated. Frank, who has never really believed in the project, sees in the pregnancy (still unwanted) the opportunity to keep his family in Revolutionary Hill; April, on the contrary, is ready to have an abortion in order to chase her new life. There begins a period of constant quarreling, creating a distance between them that cannot be closed. Eventually the project is abandoned. April's attempt to construe an authentic life begins to vanish gradually, then rapidly, violently, and tragically in the end. April dies, in her attempt to have the abortion.

In the following passage Frank and April are considering the possibility of having the abortion:

"You really are a much more moral person than I am, Frank. I suppose that's why I admire you." But she didn't look or sound admiring.

He tried to dismiss it with a careful shrug as he took a seat across from her. "I don't know about that. I don't see what any of this has to do with being 'moral.' I mean you know, not in any sense of conventional morality." 
She seemed to think this over for a long time as she lay back allowing one knee to sway from side to side, rocking it on the swivel of her ankle. Then: "Is there any other kind?" she asked. "Don't 'moral' and 'conventional' really mean the same thing?"

He could have hit her in the face. Of all the insinuating, treacherous little - Christ! And in any other month of his married life he would have been on his feet and shouting: "Christ, when are you going to get over this damn Noël Coward, nineteentwenties way of denigrating every halfway decent human value with some cute, brittle, snobbish little thing to say? Listen!" he would have raged at her. "Listen! Maybe that's the way your parents lived; maybe that's the kind of chic, titillating crap you were raised on, but it's about time you figured out it doesn't have a God damned thing to do with the real world." It was his knowledge of the calendar that stopped his mouth. There were twelve days to go. He couldn't afford to take any chances now, and so instead of shouting those things he held his jaws shut and stared at his glass, which he gripped until it nearly spilled with trembling. Without even trying, he had given his most memorable facial performance to date. When the spasm was over he said, very quietly:

"Baby, I know you're tired. We shouldn't be talking about it now. I know you know better than that. Let's skip it."

"Skip what? You know I know better than what?"

"You know. This business about 'moral' and 'conventional'."

"But I don't know the difference." She had come earnestly forward on the sofa, had drawn her sneakers back under it and was leaning toward him with both tense forearms on her knees. Her face was so innocently confused that he couldn't look at it. "Don't you see, Frank? I really don't know the difference. Other people seem to; you do; I just don't, that's all, and I don't think I ever really have."

"Look," he said. "First place, 'moral' was your word, not mine. I don't think I've ever held any brief for this thing on moral grounds, conventional or otherwise. I've simply said that under these particular circumstances, it seems pretty obvious that the only mature thing to do is go ahead and have the -"

"But there we are again," she said. "You see? I don't know what 'mature' means, either, and you could talk all night and I still wouldn't know. It's all just words to me, Frank. I watch you talking and I think: Isn't that amazing? He really does think that way; these words really do mean something to him. Sometimes it seems I've been watching people talk and thinking that all my life" - her voice was becoming unsteady - "and maybe it means there's something awful the matter with me, but it's true. Oh no, stay there. Please don't come and kiss me or anything, or we'll just end up in a big steaming heap and we won't get anything settled. Please stay sitting there, and let's just sort of try to talk. Okay?" "Okay." And he stayed sitting there. But trying to talk was something else again; all they could do was look at each other, heavy and weak and bright-eyed in the heat.

"All I know," she said at last, "is what I feel, and I know what I feel I've got to do." (Yates 2000: 222-3)

I take April to be (unsuccessfully) trying to reach what Cavell calls "the salvation of the self through the repudiation of morality." The idea that morality can be repudiated reflects a noncoercive conception of rationality that allows for the possibility of seeing morality as limited, but it also imply that its limits cannot be traced in advance. As we have seen, Cavell introduces that idea of repudiation in the context of a discussion of moral disagreement in which he radically criticizes the non-cognitivist claim that the persistence of disagreement in ethical disputes is a sign of the irrationality of morality. If I understand Cavell's point, to recognize the limits of morality means in this respect that there are circumstances in which a rational resolution of moral disagreement is attained by an agreement to disagree. That is to say that rational resolution is not always a matter of bringing others around to one's own moral convictions; it is sometimes a matter of 
agreeing to disagree. But pertaining to the sphere of first-person conflict, the idea of repudiation suggests a further way of understanding the 'limits of morality.' It suggests that an authentic assent to the moral form of life is never just a matter of sharing the conventions and the practices we inherited through upbringing, but also depends on a preliminary questioning and challenging those conventions and practices. The limits of morality are in this sense not traceable in advance, that is, independently of personal contribution and imaginative effort. But as the example above shows, questioning our assent to morality may lead to a non-ordinary experience of conceptual inadequacy, or inexpressibility. April is in fact trying to break the conventions of her moral community, because she feels that she cannot be herself (or become the person she wants to be) and carry on favoring the standards imposed on her by that community. Yates is effective in describing the difficulty of assuming the responsibility for the moral position we take. In trying to do so, April exposes herself to the risk of losing reality as graspable: her personal transformation puts her in the condition of not recognizing anymore reality as her reality. Her experience can be understood as a difficulty of reality in Diamond's sense because she feels that she can no longer speak within the ordinary language games of her community. Indeed, in losing the capacity to distinguish between "moral" and "conventional," April encounters a particular difficulty with words that discloses reality as essentially resistant to her ways of thinking and talking about it, as at once inexplicable and isolating.

Now I want to focus on the disagreement between April and Frank. In the quoted dialogue the disagreement marks the beginning of a tragedy: the distance between Frank and April is not simply a question about the legitimacy of abortion as a practical solution in view of moving to Paris, but it has to do with a radical difference of vision, which exposes April to an experience of separateness and isolation that becomes critical as the story unfolds. Frank thinks that the "the only mature thing to do" is to have the baby and give up the idea of leaving: his feigned resoluteness is due to opportunism and hypocrisy (he has already accepted the new job), but his opposition to abortion is the outcome of a conception of values as fixed principles that determine in advance the possibilities for personal articulation and imaginative understanding of the moral life. We can see how Frank uses the question of abortion to deflect from the real problem that distances him from his wife: a very different conception of life. What is for him a space of determined possibilities, is for April an adventure, in which the possibilities are still in a large part to be determined. April and Frank disagree in the way they perceive the relevance of abortion: whereas for Frank there's a principle one needs to conform to (having an abortion is against nature), April lives the tragedy of feeling the option of having the abortion as a natural necessity, that is, as a necessity of her nature. Since deciding to move to Paris, April engaged in a path of knowledge which will lead her to isolation from her moral community: this sense of separateness is reflected in the fact that the concepts which defined that community (family, abortion, job, maturity, etc.) have for her no sense anymore, nor do they grasp reality.

In Diamond's terminology, we encounter a difficulty of reality when we live an experience that puts into question our ordinary way of speaking. In the kind of disagreement which divides the Wheelers we can see the difficulty internal to the problem of the knowledge of ourselves: April experiences the radical impoverishment of her conceptual horizon, the inability to express her own vision and to grasp the world with her own voice. Frank's response to such an extreme loss is precisely a denial of 
April's experience: in deflecting towards the question of abortion and in centering only on that problem, he treats April's tragedy as a childish whim, or worse, he sees in it the symptom of a disease of personality. The dialogue quoted goes on with Frank inviting April to "rationalize" her position:

"Look," he was saying, "this may sound as if I think there is something 'awful' the matter with you; the fact is I don't. I do think, though, that there's one or two aspects to this thing we haven't really touched on yet, and I think we ought to. For instance, I wonder if your real motives here are quite as simple as you think. I mean isn't it possible there are forces at work here that you're not entirely aware of? That you're not recognizing?"

She didn't answer, and in the darkness he could only guess at whether she was listening or not. He took a deep breath. "I mean things that have nothing to do with Europe," he said, "or with me. I mean things within yourself, things that have their origin in your own childhood - your own upbringing and so on. Emotional things." There was a long silence before she said, in a pointedly neutral tone: "You mean I'm emotionally disturbed."

"I didn't say that!" But in the next hour, as his voice went on and on, he managed to say it several times in several different ways. Wasn't it likely, after all, that a girl who'd known nothing but parental rejection from the time of her birth might develop an abiding reluctance to bear children?

"I mean it's always been a wonder to me that you could survive a childhood like that," he said at one point, "let alone come out of it without any damage to your you know, your ego and everything." She herself, he reminded her, had suggested the presence of something "neurotic" in her wish to abort the first pregnancy, on Bethune Street - and all right, all right, of course the circumstances were different this time. But wasn't it just possible that something of the same confusion might still exist in her attitude? Oh, he wasn't saying this was the whole story - "I'm not qualified to say that" - but he did feel it was a line of reasoning that ought to be very carefully explored.

"But I've had two children," she said. "Doesn't that count in my favor?"

He let these words reverberate in the darkness for a while. "The very fact that you put it that way is kind of significant," he said quietly, "don't you think? As if having children were a kind of punishment? As if having two of them could 'count in your favor' as a credit against any obligation to have another? And the way you said it, too - all defensive, all ready to fight. Jesus, April, if you want to talk that way I can come right back at you with another statistic: you've had three pregnancies and you've wanted to abort two of them. What kind of a record is that? Oh, look." He made his voice very gentle, as if he were talking to Jennifer.

"Look, baby. All I'm trying to suggest is that you don't seem to be entirely rational about this thing. I just wish you'd think about it a little, that's all."

"All right," her voice said bleakly. "All right, suppose all this is true. Suppose I'm acting out a compulsive behavior pattern, or whatever they call it. So what? I still can't help what I feel, can I? I mean what're we supposed to do about it? How am I supposed to get over it? Am I just supposed to Face Up to my Problems and start being a different person tomorrow morning, or what?"

"Oh, baby," he said. "It's so simple. I mean assuming you are in some kind of emotional difficulty, assuming there is a problem of this sort, don't you see there is something we can do about it? Something very logical and sensible that we ought to do about it?" He was weary of the sound of his own voice; he felt he had been talking for years. He licked his lips, which tasted as foreign as the flesh of a dentist's finger in his mouth ("Open wide, now!"), and then he said it. "We ought to have you see a psychoanalyst.” (Yates: 2000: 224) practical difficulty into an intellectual dispute about the legitimacy of abortion. In fact he 
invites April to hesitate, he asks her to think about "the real motives" which make her desire the abortion, and puts forward a psychological explanation of the problem, in order to convince April to talk with an analyst. And it is this hesitation, the instilled suspicion of a neurosis as an explanation for her condition, that will make the hope of a change definitively collapse. (I find it noteworthy that Yates represents Frank as experiencing his own words "as foreign as the flesh of a dentist's finger in his mouth": by endorsing the values of the community in an uncritical way, he becomes alienated to himself, and the very sound of his voice becomes strange to him, but that strangeness is not experienced by him as a difficulty in Diamond's sense, and rather it shows an 'absence of morality').

But what would it mean to understand April's position in a non-deflected way? At the end of DRDP Diamond asks in a similar vein: "Can there be such a thing as philosophy that is not deflected from such realities?," that is, a philosophy capable of staying at the level of the difficulties of reality? And which is the level of the difficulties of reality? Is that something we can understand as a determinate point of view on the world, a perspective that can be occupied by a person finding herself in particular conditions? Or is it rather an apparent position from which no intelligible representation of the world can be satisfying? According to Diamond, the answer to such questions is related to Wittgenstein's aim of bringing words back from their metaphysical to their everyday use. In the second section of this paper I discussed Cavell's idea that disagreement is a fact of our ordinary language, that this fact is part of our natural modes of responsiveness; so now, following Diamond and Cavell, the question might be put this way:

What can the difficulty be, then, of bringing or leading words back? What is the everyday, if it is so hard to achieve? It is within the everyday that there lie the forms and varieties of repudiation of our language-games and distance from them, the possibility of being tormented by the hiddenness, the separateness, the otherness of others. (Cavell, Declining Decline, quoted in DRDP: 113)

We have seen that April's encounter with a difficulty of reality has the form of a dissatisfaction with the ordinary language-games that articulate the moral life of her community. In finding the 'limits of morality', she cannot reach a meaningful description that could accommodate her attitude towards the world. From this point of view, to acknowledge her position without deflecting means to follow her in the impossibility to give a determinate sense to words such as 'moral' and 'conventional.' Indeed, as we have seen in Frank's response, to try to make sense of April's position by treating it as an ordinary matter (by, for example, offering a psychological explanation of "the real motives" of her behavior, or talking about the problem of abortion) means precisely to deny those qualities of her experience that make it difficult in the relevant way. The only way to acknowledge the difficulty of reality here is to imaginatively participate in the 'sideways-on' perspective from which April looks at the world, in the very same way in which, according to Diamond, the reader of Wittgenstein's Tractatus is required to enter imaginatively into the nonsensical sentences that make up the book. ${ }^{2}$ If this is true, Diamond's commitment to what she calls "the realistic spirit" in philosophy requires, at least when confronting with a difficulty of reality, an understanding of "the ordinary" as the locus in which our life with words may become problematic and strange, not the quietistic achievement of a condition in which our problems disappear. 
I picked up the example of April and Frank Wheeler because it shows us a kind of distance between human beings in which what is at stake is not a judgment about the rightness of an action, or the legitimacy of a choice. Meta-ethical analyses, because of their comparing moral judgments with factual or scientific ones, tend to conceive moral disagreements only as disagreements about how things are in the world. But April and Frank Wheeler do not disagree about particular judgments, they are divided in the way they respond to life, in the way they use their concepts to structure their life and understand others. What divides them has not the aspect of a factual disagreement. In the example the situation is complicated by the fact that April experiences a sense of separateness that flings her away from her own mode of thinking and talking, and this represents a kind of difficulty that philosophy should be able to account for without deflecting.

31 I want to conclude with some brief remarks about the consequences of the conception of moral discourse and thought favored here for the problem of objectivity in ethics. Both Diamond and Cavell have drawn from Wittgenstein a conception of rationality and of language as a range of possibilities in which the application of concepts is not fixed by external rules and independently from personal contribution. One of the possibilities we have is that of calling into question our conceptual horizon, that is the possibility of feeling that our words have lost their grasp on the world, and this define the kind of difficulty I have been concerned with.

It may seem, though, that if we follow Cavell and Diamond in thinking that a nonmoralistic conception of morality should allow for the possibility of seeing morality as limited, then we must recognize that ethics is just a matter of subjective articulation. But this conclusion seems inevitable only on the ground of a widespread assumption about the concept of objectivity that excludes the subjective (that is perceptual and affective) endowments we draw on in thinking about the world because they tend to distort our view of reality. Alice Crary calls this conception the "narrow conception of objectivity" (Crary 2007: 18-29), which is the result of a philosophical requirement that any inquiry aiming at calling itself objective must establish that there is a reliable connection between its conceptual space and some realm independent of it. In this paper I tried to show that the idea of the "limits of morality" "does not instantiate a single concept," where this means that persons find different ways of articulating their moral views that cannot be determined a priori. We just do not know what people will find important and worthy of value, and so we should resist the deflecting effort to construct a theory of moral disagreement or objectivity.

In the light of Diamond's conception I have sketched above, that morality be objective can plausibly mean that the aspirations to deepen our moral views and resolving our conflicts are rational. But as Cavell urges, the rationality of morality does not relieve us of responsibility for the position we take. A realistic philosophical task would be then that of looking at the various ways in which people articulate their moral experience, even when they generate idiosyncratic visions as in the example of April Wheeler. It would make headway in understanding morality as an intensely human affair. 


\section{BIBLIOGRAPHY}

CAVELl S., (1979), The Claim of Reason, Oxford and New York, Oxford University Press.

CRARY A., (2007), Beyond Moral Judgment, Cambridge (MA) and London (UK), Harvard University

Press.

DIAMOND C., (1988), “Losing Your Concepts," Ethics 98, 255-77.

DIAMOND C., (1991), "Ethics, Imagination and the Method of the 'Tractatus'," in R. Heinrich \&

H. Vetter (eds.), Bilder der Philosophie. Reflexionen über das Bildliche und die Phantasie, Wien, Oldenburg.

DIAMOND C., (2008), "The Difficulty of Reality and the Difficulty of Philosophy," in C. Wolfe \&

I. Hacking (eds.), Philosophy and Animal Life, New York, Columbia University Press.

GAITA R., (1991), Good and Evil. An Absolute Conception, Routledge, London and New York.

MCDOWELL J., (1998), Mind, Value and Reality, Cambridge (MA) and London (UK), Harvard University

Press.

PUTNAM H., (2002), The Collapse of the Fact/Value Dichotomy and Other Essays, Cambridge (MA) and London (UK), Harvard University Press.

YATES R., (2000), Revolutionary Road, New York, Vintage Contemporaries.

\section{NOTES}

1. In Part Three of The Claim of Reason Cavell is primarily concerned with criticizing Stevenson's emotivism. Although Stevenson seems hopelessly crude to contemporary and more sophisticated versions of non-cognitivism (e. g. error-theories, expressivism, prescriptivism and quasirealism), I think that what renders Cavell's point on the limitations of non-cognitivist theories still timely is his understanding of the discontinuity between ethics and science in a way that does not depend on a metaphysical distinction between facts and values. Another important difference is that Cavell does not conceive ethical meaning as a feature (neither a logical one, like in Hare's prescriptivism, nor a psychological one, like in various forms of expressivism) of ethical sentences. Cavell (like Diamond) inherited from Wittgenstein the idea that a sentence is meaningless not because it does not show some logical feature or syntactical form, but because we failed to give meaning to one or more of its components. Contemporary non-cognitivism has been criticized in a way that can accommodate Cavell's point also by John McDowell and Hilary Putnam. For a radical criticism of the distinction between facts and values see Putnam 2002; for a criticism of the "disentangling manoeuvre" in accounting for the meaning of ethical concepts, see McDowell 1998.

2. On this point see Diamond 1991. 


\section{ABSTRACTS}

In this paper I want to consider a kind of inexpressiveness that can characterize our moral experience. The acknowledgement of the possibility of failure in trying to word the world - to find adequate means of expression for our condition - deeply informs Cora Diamond's conception of language and moral thought as well as her philosophical method. In particular, in her paper The Difficulty of Reality and the Difficulty of Philosophy Diamond is concerned with a resistance by reality to one's ordinary modes of thinking and talking, the feeling of a mismatch between concepts and experience in which it is the nature of experience itself that deprives one of the words suitable to contain it.

In this paper I want to show how a particular kind of moral conflict can be perspicuously described as a difficulty of reality. This conflict occurs when we lose the ability to conceive the moral world we inhabit as ours, when, that is, our self-conceptions clash with the requirements of morality and we find ourselves in the position of not being able to say what "morality" means for us anymore.

Stanley Cavell speaks in this vicinity of the possibility of repudiating morality when it threatens our integrity. This distance between the subject and the world, the self and morality, which, in Cavell's account of perfectionism, is a precondition for the development of an authentic moral perspective, is nonetheless neglected by metathical analyses in which the prominent occurrences of ethical disagreements pertain principally to the correct application of evaluative terms.

I sketch Cavell's analysis of disagreement in the light of his discussion of moral rationality. Then I connect the topic with Diamond's notion of the "difficulty of reality," developing the link between Diamonds and Cavell's thought by using an example taken from Richard Yates's novel Revolutionary Road.

My aim will be twofold: the focus on Cavell's conception of moral rationality, on the one hand, is intended to show how the traditional meta-ethical debate about disagreement is deflected in that it cannot acknowledge this kind of conflict; on the other hand, to speak of a difficulty of reality in the context of a perfectionist account of moral life is a way to give content to the idea of morality as "limited," a way of understanding morality as of human origin. 